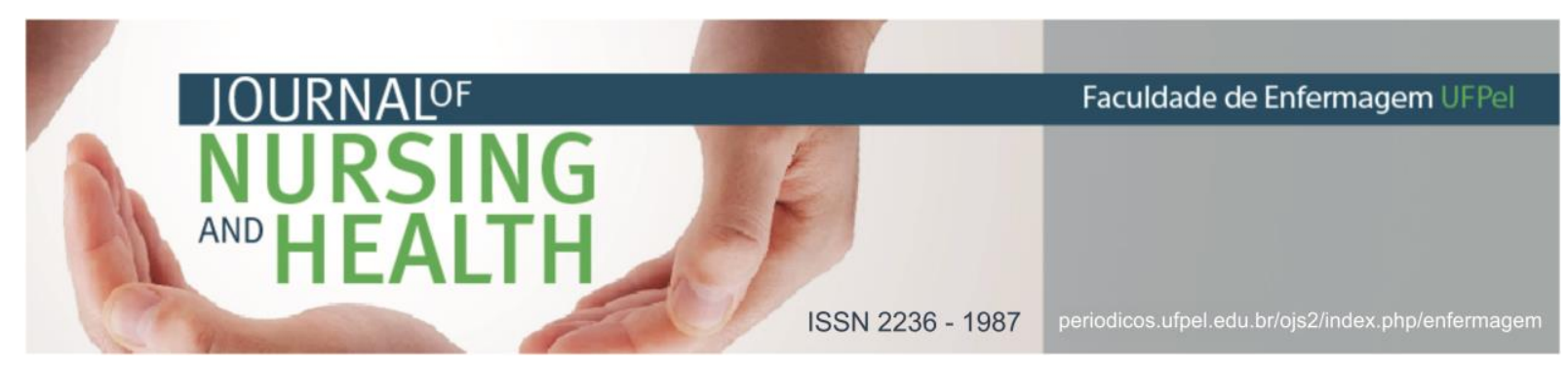

DEPOIMENTO DE EXPERT POR EXPERIÊNCIA

\title{
Do silêncio à palavra: narrativa de uma pessoa que ouviu vozes calada
}

\section{From silence to word: narrative of a person who heard voices and did not say \\ Del silencio a la palabra: narrativa de una persona que oyó voces calladas}

\author{
Zacarias, Carlos Alberto Narciso¹ Machado, Roberta Antunes²; Ubessi, Liamara Denise3; Lemões, \\ Marcos Aurélio Matos ${ }^{4}$; Borges, José Fernando do Amaral ${ }^{5}$; Kantorski, Luciane Prado ${ }^{6}$
}

Como citar este artigo: Zacarias CAN, Machado RA, Ubessi LD, Lemões MAM, Borges JFA, Kantorski LP. Do silêncio à palavra: narrativa de uma pessoa que ouviu vozes calada. J. nurs. health. 2018;8(n.esp.) e188407

Palavras-chave: Saúde mental; Ouvir vozes; Vozes.

\section{APRESENTAÇÃO}

Esta entrevista faz parte de um encontro que começou em 2015 por uma das autoras durante a construção de sua tese ${ }^{1}$, convivendo com pessoas que integram a Associação de Usuários(as) dos Serviços de Saúde Mental de Pelotas (AUSSMPE).

Entre os cinco anos de pesquisa, laços e afetos foram construídos dentro dos princípios da Luta Antimanicomial e da Reforma Psiquiátrica, resultando em conexões que levaram a algumas revelações, dentre elas, a escuta de vozes. Foi inesperado, pois muitos de nós guardávamos em um suposto segredo o fato de ouvirmos vozes, mas que a partir do encontro com o movimento de ouvidores(as) de vozes, nos permitimos a compartilhar essas experiências. Suposto segredo, pois quem sabia das nossas vozes eram os trabalhadores(as) da Atenção Psicossocial e alguns familiares.

A psiquiatria convencional ao "patologizar" a escuta das vozes, trouxe como consequência o estigma da loucura para aqueles e aquelas que ouvem vozes e até

\footnotetext{
${ }^{1}$ Integrante do Grupo Vocal Esperança, do Musical Los Lokos e da Associação de Usuários dos Serviços de Saúde Mental de Pelotas (AUMSSPE). E-mail: carloszacaria8@gmail.com http://orcid.org/0000-0001-6302-3320

2 Enfermeira. Mestre em Ciências. Instituto Federal de Educação, Ciência e Tecnologia do Rio Grande do Sul (IFRS). E-mail:roberta.machado@riogrande.ifrs.edu.br http://orcid.org/0000-0002-9087-6457

${ }^{3}$ Graduada em Psicologia e Enfermagem. Doutora em Ciências. Universidade Federal de Pelotas (UFPEL). E-mail: liaubessi@gmail.com https: //orcid.org/0000-0002-5884-9969

${ }^{4}$ Enfermeiro. Doutor em Ciências. Universidade Federal de Pelotas (UFPEL). E-mail: enf.lemoes@gmail.com http: / /orcid.org/0000-0002-6897-4130

${ }^{5}$ Integrante do Grupo Musical Los Lokos e da Associação de Usuários (as) dos Serviços de Saúde Mental de Pelotas (AUMSSPE). http: / /orcid.org/0000-0002-3376-4950

${ }^{6}$ Enfermeira. Doutora em Enfermagem. Universidade Federal de Pelotas (UFPEL). E-mail: kantorski@uol.com.br http: / / orcid.org/0000-0001-9726-3162
} 


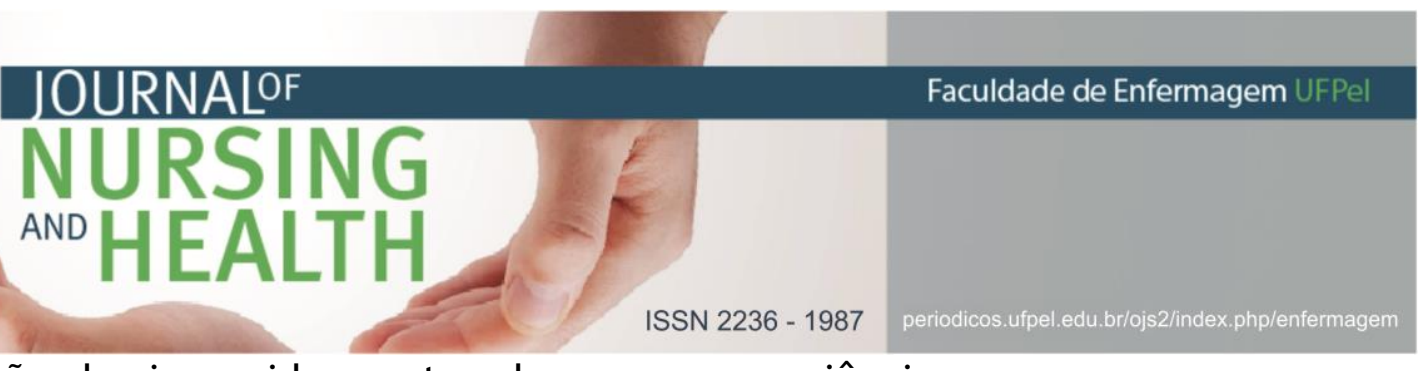

então não haviam sido capturados por essa ciência, o que promoveu um silenciamento nos sujeitos ouvidores de vozes. ${ }^{2}$

Por isso, falar sobre a escuta das vozes nesse grupo mostrou-se um comparecimento, que só foi possível, devido ao encontro com o Movimento de Ouvidores de Vozes no qual a AUSSMPE está engajada e disseminando que entendem as vozes como uma experiência subjetiva e inerente ao ser humano. Subjetiva, no sentido que cada ouvidor(a) percebe e a(s) vivencia $(\mathrm{m})$, de uma forma muito particular e singular, dando sentido e significados diversos, conforme a história de vida de cada sujeito. Inerente, ao passo que essa experiência vem sendo e pode ser vivenciada por diversas pessoas, em diferentes contextos sócio históricos, políticos e culturais. Então, ouvir vozes, pode ser um acontecimento da experiência vivida, e que "patologizar" é mais uma forma de violentar a expressão humana. Contudo, com isso não se está dizendo que em alguns momentos não sejam necessárias mediações neste processo.

O movimento de ouvidores(as) de vozes permite o compartilhamento dessas experiências entre os sujeitos que as ouvem, possibilitando uma visão diferente daquilo que os manuais de psiquiatria e alguns ditos da psicologia, enfermagem e outras áreas afirmam sobre essa vivência, rotulando a experiência de ouvir vozes e das pessoas, como um dos sintomas psicóticos.

Noutras palavras, enquanto a psiquiatria convencional busca a supressão das vozes, o Movimento de Ouvidores afirma que compartilhar a experiência tem contribuído para o lidar com as próprias vozes, que falar sobre elas, rompe com o ciclo de solidão vivenciada por alguns/algumas pessoas ouvidores (as), criado pelo estigma que envolve o fato de ouvir vozes, dado que nem todas as pessoas escutam, e por isso tendem a julgar e até a não entender quem ouve. 0 Movimento também possibilita a troca de estratégias de enfrentamento para conviver com as vozes. . $^{3-5}$

Carlos Alberto Narciso Zacaria é um compositor de músicas traduzidas em desenhos e pinturas, inspirado no seu vivido e em sua companheira Migueline dos Santos Lisboa. Em sua história atuou como profissional de enfermagem por 16 anos, em serviço hospitalar. Foi assistido por determinado tempo em um Centro de Atenção Psicossocial (CAPS). Atualmente, integra o Grupo Vocal Esperança, o Musical Los Lokos e a AUSSMPE. A partir do contato com o movimento de ouvidores (as) de vozes, via apresentação do Los Lokos em evento que tematizava justamente o "ouvir vozes", promovido pelo curso de Psicologia da Universidade Católica de Pelotas (UCPel), Carlos narra sua experiência com as vozes. E desde então, um artista que "pintava" suas vozes em telas e músicas (Figuras 1 e 2), agora as narra também em palavras.

\section{Conosco e com vocês, as vozes na voz de Carlos:}

Ouvir vozes foi uma experiência que me causou muito sofrimento. Hoje eu não as ouço, mas em 2003 eu quase internei, por causa da experiência negativa que eu tive com elas. Foi uma experiência muito intensa, pois as vozes me diziam 


\section{NURSING \\ AND

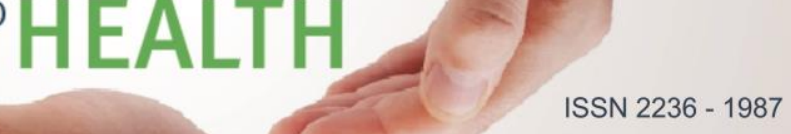

coisas que me abarrotavam, me puxava para baixo, não eram vozes positivas, era tudo bem negativo. Quando as vozes surgiram eu achei que eram espíritos, pois eu também sentia cheiros de flores, cheiro de remédio.

As vozes me acompanhavam em casa e no trabalho, mas nunca contei para ninguém, pois tinha medo de ir para o psiquiatra e perder o serviço, então eu as enfrentei sozinho, em silêncio, o que foi uma experiência bem sofrida e no final das contas acabei perdendo o serviço. Em uma demissão em massa, eu acabei sendo demitido. Trabalhava no hospital como técnico em enfermagem. Eu percebo que deveria ter me tratado desde essa época, pois eu estava bem fragilizado, passando por um período bem difícil na minha vida, o que me deixou emocionalmente abalado.

Até hoje eu não sei o que pensar sobre quem ouve vozes, se eu aprendi algo com a minha experiência, pois para mim foi tão sofrido e complicado. Eu me questionava o motivo de eu ouvir vozes, busquei o espiritismo para entender, mas acabei desistindo de frequentar e de saber os motivos que o espiritismo tinha para as minhas vozes.

Eu tinha uma postura muito passiva em relação as vozes, eu não discutia com elas e não falava com ninguém sobre elas, na verdade eu não tinha com quem compartilhar. Por ter enfrentado essa fase sozinho, posso dizer que fui forte em não fazer alguma coisa, pois eu cheguei a pensar que iria enlouquecer.

Mesmo sabendo que cada pessoa que ouve vozes vai ter uma reação, hoje eu penso que a pessoa precisa procurar ajuda, falar sobre elas e não ficar com todo esse sofrimento para si, assim como eu fiquei, esse é o meu conselho, o de uma pessoa que ouviu vozes por muito tempo em silêncio.

Eu silenciei as vozes porque a primeira coisa que a gente pensa é que está enlouquecendo, eu só fui falar que ouvia as vozes agora que eu ouvi o depoimento do grupo [Los Lokos no evento promovido pelo curso de Psicologia da UCPel], aí eu me animei e resolvi falar, senti que eu tinha que falar, que dessa vez eu não iria ficar calado.

Buscar um tratamento foi importante para mim. Em 2004 eu fui para o CAPS aqui em Pelotas, foi aí que eu comecei a melhorar e passei a não ouvir mais. Eu não sei se uma pessoa consegue viver ouvindo vozes, principalmente se elas forem negativas, se for vozes positivas pode até conseguir, mas se as vozes são muito negativas, a experiência é muito sofrida. No meu caso, as vozes diziam que eu estava morto, e eu me tocava e não sentia o meu corpo, era como se só meu pensamento estivesse funcionando, pois eu realmente não me sentia, mesmo eu me apalpando, eu não sentia meu corpo. 


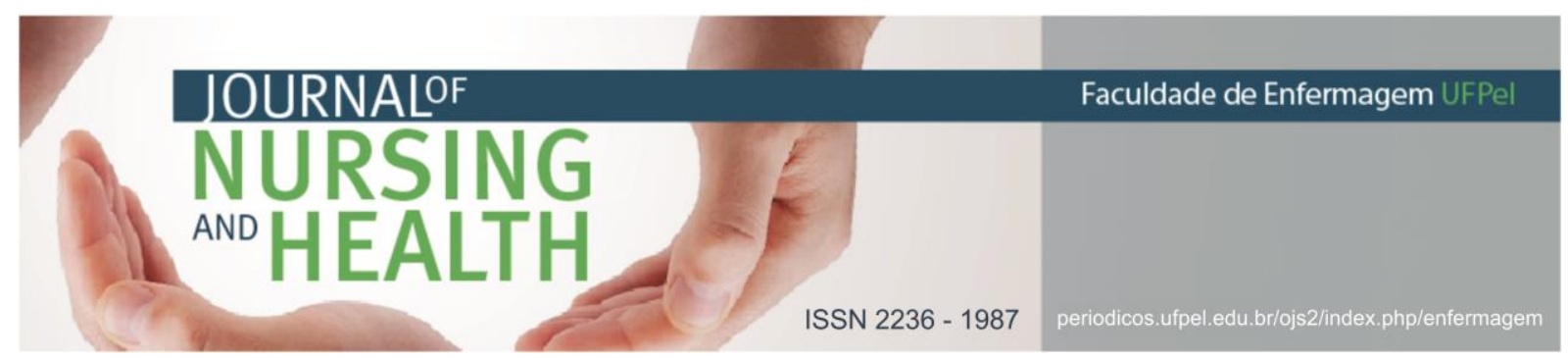

Hoje se um pensamento negativo vem na minha mente, eu oro muito, e isso me ajuda, eu me converti ao cristianismo e eu me apego muito a religião como uma estratégia para enfrentar os pensamentos negativos.

Até pouco tempo eu não tinha conhecimento sobre o Movimento de Ouvidores de vozes, mas eu creio que é um movimento bom, bem positivo, encoraja as pessoas a falarem sobre as vozes, por exemplo, eu que nunca tinha falado sobre elas, me animei a falar e foi bom.

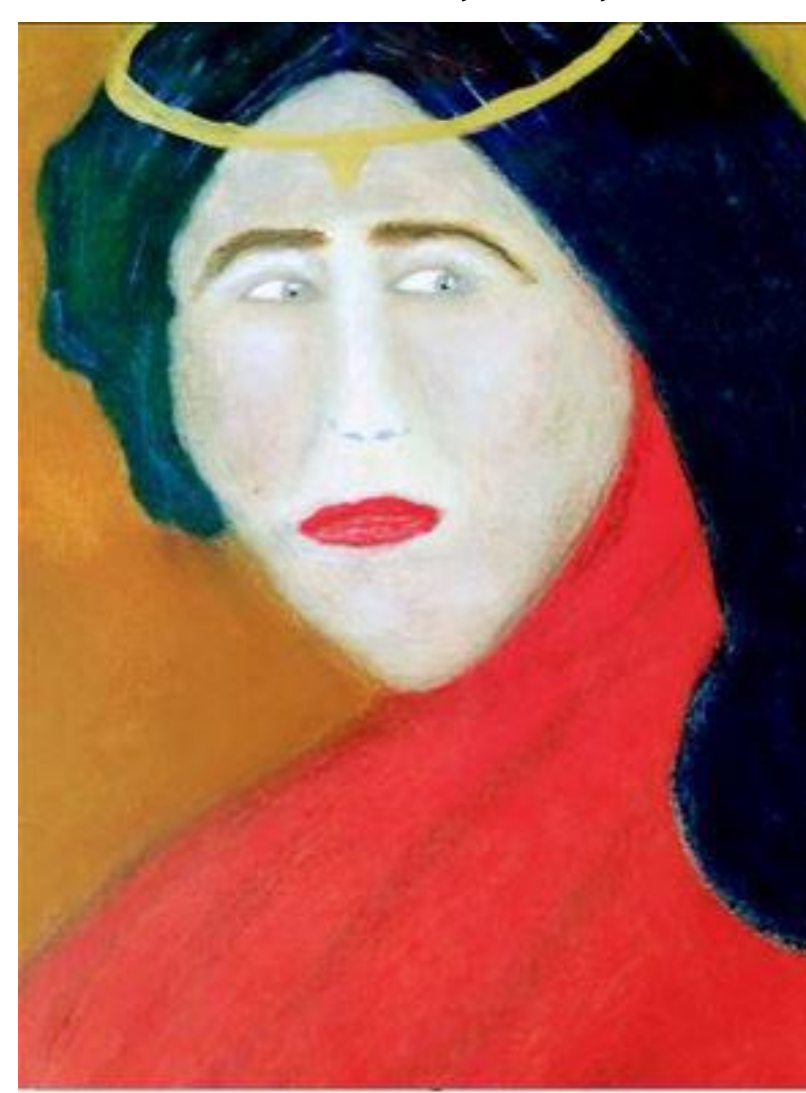

Figura1 - Produção Artística de Carlos Alberto Narciso Zacaria

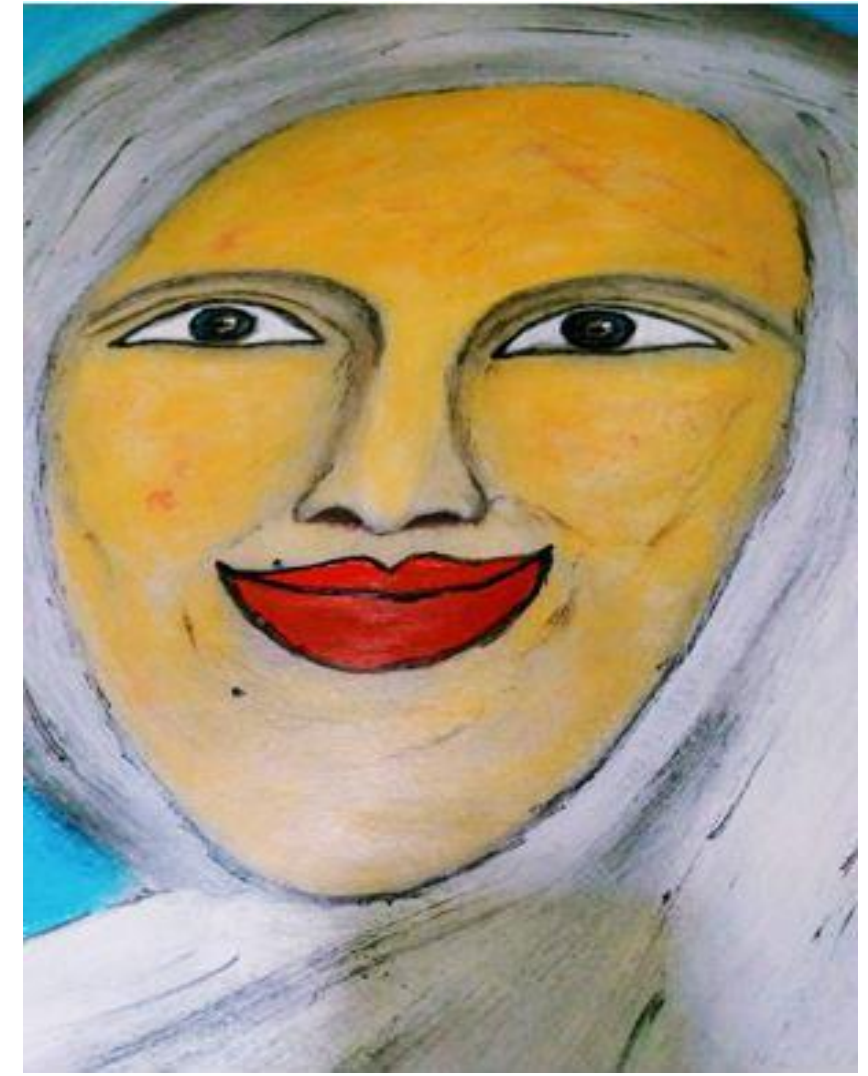

Figura 2- Produção artística de Carlos Alberto Narciso Zacaria

\section{REFERÊNCIAS}

1. Ubessi LD. A loucura das águas da não indiferença na produção de diferença uma estética de rexistências em paisagens do Sul. [Tese]. Pelotas (RS): Universidade Federal de Pelotas; 2017.

2. Foucault M. História da loucura na Idade Clássica. São Paulo: Perspectiva; 2008.

3.Kantorski LP, Antonacci MH, Andrade APM de Cardano M, Minelli M. Grupos de ouvidores de vozes: estratégias e enfrentamentos. Saúde debate [Internet]. 2017 dez[acesso em 2018 mar 31];41(115):1143-1155. Disponível em: 


\section{JOURNALOF \\ NURSING \\ AND}

ISSN $2236-1987$

http: / /www.scielo.br/scielo.php?script=sci_arttext\&pid=S0103$11042017000401143 \& \operatorname{lng}=e n$

4.Kantorski LP, Andrade APM de Cardano M. Estratégias, expertise e experiências de ouvir vozes: entrevista com Cristina Contini. Interface (Botucatu, Online) [Internet]. 2017 dez[acesso em 2018 mar 31];21(63):1039-1048. Disponível em: http: / / www.scielo.br/scielo.php?script=sci_arttext\&pid=S141432832017000401039\&lng=en

5. Barros OC, Serpa JOD de. Ouvir vozes: um estudo sobre a troca de experiências em ambiente virtual. Interface (Botucatu, online) [Internet]. 2014 set[acesso em 2018 mar 31];18(50):557-69. Disponível em: http: / / www.scielo.br/scielo.php?script=sci_arttext\&pid=S1414$32832014000300557 \& \operatorname{lng}=\mathrm{en}$

Data de publicação: 19/09/2018 